\title{
REFLEXIONES SOBRE LA HOMOSEXUALIDAD EN LA HISTORIA DEL IMPERIO ROMANO: IMPACTOS EN LAS SOCIEDADES DEL REINO DE PORTUGAL Y EN SU COLONIA DE BRASIL
}

\author{
REFLECTIONS ON HOMOSEXUALITY IN THE HISTORY OF THE ROMAN EMPIRE: \\ IMPACTS ON THE SOCIETIES OF THE KINGDOM OF PORTUGAL AND IN ITS COLONY OF \\ BRAZIL
}

\section{Douglas Verbicaro Soares}

Universidade Federal de Roraima, Boa Vista, RR, Brasil. E-mail: douglas_verbicaro@yahoo.com.br

\author{
DOI: https://doi.org/10.46550/amormundi.v2i3.51
}

Recebido em: 12.02.2021

Aceito em: 21.03.2021

\begin{abstract}
Resumen: El estudio tiene como objetivo visibilizar la práctica de la homosexualidad en la historia de la humanidad, en destaque en el período del Imperio Romano y, también, sus impactos en la Edad Moderna en el Reino de Portugal y su Colonia en América. Para eso, ha sido realizada una investigación basada en fuentes bibliográficas que retrataron esas prácticas en un período único del pasado, explicitando también su posterior condena con el surgimiento de preceptos de la religiosidad cristiana de la época. Para la investigación ha sido empleada una metodología basada en la fuente bibliográfica multidisciplinar, con relación con el arte, el derecho, la historia, etcétera. El estudio concluye por la perpetuación histórica de ideario discriminador para la homosexualidad en el tiempo, pues en la actualidad, ciertos argumentos previstos en discursos de origen religiosa siguen en la diseminación del odio contra la diversidad sexual en diversas sociedades por el mundo.
\end{abstract}

Palabras-claves: Condena. Roma. Homosexual. Discriminación.

Abstract: The study aims to make visible the practice of homosexuality in the history of humanity, highlighting in the period of the Roman Empire. For this purpose, research has been carried out based on bibliographic sources that portrayed these practices in a unique period of the past, also expressing his subsequent condemnation with the emergence of precepts of Christian religiosity of the time. For research has been used a methodology based on the multidisciplinary bibliographic source, in relation to art, law, history, etc. The study concludes with the historical perpetuation of discriminatory ideary for homosexuality over time, as today, certain arguments provided for in discourses of religious origin continue to spread hatred against sexual diversity in various societies around the world.

Keywords: Condemnation. Rome. homosexual. Discrimination. 


\section{Introducción}

T a historia ha visibilizado hechos que demuestran la persecución a las prácticas homosexuales, principalmente a partir de la propia materialización del Cristianismo como religión perteneciente al Imperio Romano (AYENSA, 2008, p. 28). En ese sentido, existían por ejemplo: las leyes del Imperio Romano, que especificaban: vergonzosa costumbre de condenar el cuerpo de un hombre a desempeñar el papel de mujer, hombres que comentan liviandades con los hombres.

Del mismo modo, está presente en la propia historia de Roma, distintos personajes relacionados con la homosexualidad, entre ellos: los Scortum, que serían hombre de segunda clase, donde los ciudadanos romanos podrían mantener prácticas sexuales de un modo lícito, es decir, a través de la prostitución con eses hombres. La situación generalmente era ejercida por hombres esclavos, que tenían sus dueños (los Lenones, padrotes) como negociantes de sus cuerpos a otros hombres en el medio social en que vivían. Tanto es cierto que se hablaba de la ocurrencia de un día específico para la celebración de los servicios prestados por los hombres padrotes que ejercitaban la prostitución masculina (IZQUIERDO, 2006, p. 9). Otros instrumentos normativos de Roma eran las tipicidades en sus normas de las prácticas consideradas ilícitas en sociedad, que protegieron a los hijos de Roma (los praetextati), es decir, los ciudadanos romanos, en la etapa previa de la niñez y de la adolescencia, para que no fuesen confundidos con los jóvenes esclavos. (IZQUIERDO, 2006, p. 15-6).

Además de punir determinadas conductas sociales, como ha sido en el caso de castigar a los ciudadanos romanos que mantuviesen prácticas sexuales con la esposa de otro romano. Entre los modos de punir estaban: la pena del rábano y el mújol, donde el marido de la mujer adúltera podría violar sexualmente el amante de su mujer, o también, hacer con que el amante fuese entregue a uno de los esclavos del esposo de la mujer adúltera (para que éste fuese violado). En la condena también podría ser sodomizado en persona, tener la nariz o las orejas cortadas, o la sumisión al felatio (que le despojarían de su virilidad), incluso la previsión del homicidio para el amante como castigo por sus conductas (IZQUIERDO, 2006, p. 23-4).

Del mismo modo, las prácticas homosexuales entre mujeres también eran consideradas como anti-natural y como adulterio: el amor entre lesbianas es en primer lugar contra natura, y en segundo lugar criminal. La mujer casada que tiene una relación de este tipo comete adulterio (IZQUIERDO, 2006, p. 24-5).

Para la investigación ha sido empleada una metodología basada en fuente bibliográfica multidisciplinar, con relación con el arte, el derecho, la historia, etcétera. El estudio tiene dos (2) apartados, más la introducción, consideraciones finales y bibliografía. El primero versa sobre la condena de la homosexualidad en el Imperio Romano. El segundo retrata los impactos de la persecución de la Edad Media también en otras sociedades de la Era Moderna: especial referencia al Reino de Portugal y su Colonia (Brasil) en América.

De ese modo han sido realizadas algunas preguntas para el estudio: ¿Cómo surgió la condena a la práctica de la homosexualidad en el Imperio Romano? ¿Esa condena de la Edad Media ha impactado en sociedades en un periodo posterior, como por ejemplo en la Era Moderna? 


\section{La condena de la homosexualidad en el Imperio de Roma}

Con Constantino (MALUCELLI, et al., 2010, p. 28-34), se proliferó en la sociedad de la época la ideología de que la homosexualidad en sí representaría un riesgo grande al Imperio, utilizando así la idea de que las relaciones sexuales deberían ser realizadas con el objetivo primordial en la reproducción humana y la manutención hereditaria de la misma. Hechos eses que por sí alejaban y condenaban las prácticas homosexuales, una vez que naturalmente imposibilitan la perpetuación de la especie (ROBERT, 1999, p. 125-6).

Para corroborar con esta idea, a finales de la República, ocurre un rompimiento de los tabús, generando una apertura de las reivindicaciones en sociedad por el deseo sexual. Según Jean-Nöel Robert:

La influencia del epicureísmo y la poesía alejandrina reafirmaron a algunos jóvenes de Roma en su voluntad de clamar sus sentimientos a la vez que les inspiró las adecuadas para hacerlo. Un ejemplo seria lo de Memmio, protector de Lucrecio, epicúreo y buen vividor, cuya existencia acabó en el exilio, en Atenas (ROBERT, 1999, p. 125-6).

Según Robert (1999) a él se le gustaba componer poemas, sobre todo con contenido erótico. Se comentaba que al partir a otra zona de la ciudad en la cual vivía, se marchó con su séquito, cocineros e etcétera, donde posiblemente se encontraban Lucrecio, Cinna y Catulio. Al último nombre, se le atribuía la generosidad no solo para escuchar a las obras artísticas creadas, pero que también, la compañía debería tener un contacto físico más personal entre el patrón y su subordinado (ROBERT, 1999, p. 126).

Esa visión de la práctica sexual como una extensión motivadora del acto de generar y reproducir la especie humana ha condenado el placer de la sexualidad a un espacio más reducido, donde las conductas que se alejaban de esta idea, estarían relacionadas con el pecado, con el prohibido, lo maligno, etc...

De este modo, la exteriorización del deseo humano, es decir, de la sexualidad del hombre, al aflorarse de modo diverso del tradicional seguido/impuesto socialmente en la sociedad de la época. Que en este caso, la romana, al que se refiere al final de la República, los impulsos de muchos hombres a la libido sexual se satisfacía junto a otros hombres con el mismo deseo, en este caso la visión del sexo y el amor eran comprendidas de modos completamente antagónicos. La primera por la idea de satisfacción de un placer carnal, donde el cuerpo de la otra persona al cual se practicaba el acto seria indiferente (hombre o mujer) (VERBICARO SOARES, 2015, p. 84). En este sentido, la idea del amor era dejada de lado y la orientación del deseo bisexual era más que aceptada en el medio social y no cuestionada para este fin de satisfacer los deseos humanos.

Para este pensamiento, se hace fundamental la citación de Lucrecio, que se le atribuye ser el primer poeta romano que se manifestó frente a la pasión amorosa y la expuso como un tipo de enfermedad. Según sus palabras:

Conviene rechazar todo lo que pueda alimentar nuestro amor, dirigir nuestro espíritu hacia otros objetos; es preferible derramar el licor acumulado en cualquier cuerpo, que guardarlo para un único amor que nos ate por completo. A buen seguro, los que mantienes la cabeza sana disfrutan de un placer más puro que los pobres extraviados [...] la pasión amorosa ciega a los hombres que posee y éstos atribuyen a las amadas unos méritos que no les corresponden (ROBERT, 1999, p. 129-31). 
De este modo, se nota la grande preocupación en poner el amor en una posición secundaria y donde se le coloca sobre el mismo una idea de que es peligroso, algo que asusta, que genera un temor, que sería algo desconocido y que no valdría la pena vivir, es decir: mantenerse alejado de él para conservar el dominio sobre sí mismo (ROBERT, 1999, p. 131).

Nöel Robert nos recuerda que, al explicitar Lucrecio, informa que al finales de la República de Roma, eran comunes las prácticas sexuales bisexuales, aunque perduraría la idea de que el hombre debería ser la persona dominante, de poder satisfacer a sus propios deseos aflorados, algo normal en un romano. En este sentido, los que se consideraban anormales serían los que no hiciesen caso a eses deseos de practicar sexo con una persona del mismo sexo. La idea de moral para la sociedad de la época sería a de no llevar en consideración el amor en la vida (en el cotidiano de las personas). Para un ciudadano romano lo que importaba era la obligación de generar un heredero y de que su mujer fuera fértil para lograr ese objetivo primordial (ROBERT, 1999, p. 125).

A lo largo de las consideraciones supra citadas, se puede entender que los encuentros sexuales entre los ciudadanos romanos, es decir: entre hombres, eran vistos como normales y sobretodos habituales. Desde que respetasen algunos requisitos, tales como: que fuesen realizados por un ciudadano romano y una persona en situación de inferioridad, generalmente un esclavo; que esta conducta sexual no implicase en la no obligación del ciudadano romano con el Estado; y por fin, que esta práctica fuese realizada por el ciudadano romano y que a él fuese atribuido en rol de activo en la relación sexual homosexual (AYENSA, 2008, p. 128).

La persecución a los homosexuales se intensificará con la tipificación de la homosexualidad como un crimen en el Derecho Romano, siendo el Código de Justiniano, de la época 529 d. C. la materialización de esa tipología. Según el texto mencionado: las personas que se prestasen a la homosexualidad deberían ser ejecutadas, pero también, había la previa que las personas arrepentidas que podrían ser salvadas de la pena capital. Ese período histórico impulsará la condena a la homosexualidad (DO BOMFIM, 2011, p. 78).

El autor sigue en sus argumentos aduciendo que en el periodo de 342 d.C., ya existía la previsión legal de condena al casamiento entre personas del mismo sexo. Con la crisis del Imperio Romano, se vuelve a manifestarse socialmente una tolerancia a las prácticas homosexuales, en los reinos bárbaros que se forman a posteriori. La excepción era el Reino de Espańa. En el Siglo XIII, un cambio ocurre en Europa, con la ascensión de la Iglesia Católica Apostólica Romana, que con la tipificación del crimen de sodomía reflejará en la no aceptación y condena de la homosexualidad por el mundo occidental (DO BOMFIM, 2011, p. 78).

Con el adviento del III Concilio de Latrón, en 1179, se condena por primera vez la homosexualidad por la Iglesia, siendo que todas las personas que fuesen pilladas en actos de sodomía tendrían la punición según el grado de jerarquía de la persona que lo cometiera, si era perteneciente al clero o por ser una persona poco esclarecida. Ese período de persecución se extenderá por toda la Edad Media (VERBICARO SOARES, 2015, p. 86). Del mismo modo, sus impactos estarán justificados en otros períodos históricos, en diversas sociedades por el mundo, por ejemplo en la Era Moderna, con el Reino de Portugal. 
3 Los impactos de la persecución de la Edad Media también en otras sociedades de la Era Moderna: especial referencia al Reino de Portugal y su Colonia (Brasil) en América

Es válido recordar que los efectos de esta condena se verán reflejados en las colonias en el Nuevo Mundo (ya en el periodo de la Edad Moderna). En este caso, Brasil, como una Colonia del Reino Portugués, con la influencia del Ordenamiento del Reino en los temas relacionados a la condena a la homosexualidad. En ese sentido mencionaremos las Ordenaciones Afonsinas, las Manuelinas y las Filipinas, que tipificarían la homosexualidad y la punirían con la pena de muerte en la hoguera (VERBICARO SOARES, 2015, p. 86).

Mott (1997) nos recuerda que con el Tribunal de Inquisición, en el período de 15361821, la represión a los sodomitas, siendo después de los judíos, la minoría que más ha sufrido las persecuciones de los idearios de la Iglesia Católica Apostólica Romana. Se han encontrado en los archivos portugueses los registros de casi cinco mil denuncias contra a personas, supuestamente, homosexuales, entre lusos y brasileños. Dentro de los cuáles, más de 400 han sido detenidos, sentenciados, punidos con castigos físicos como azotes, expulsados de los territorios de la Corona Portuguesa y, también, condenados a la muerte, quemados en las hogueras en nombre de Dios, en los actos de fe (MOTT, 1997, p. 06).

La primera Ordenación trabajada, la Afonsina, de 1446, tenía la condena expresa de la homosexualidad en el Libro V, Título XVII - de los que cometiesen el pecado de sodomía (DO BOMFIM, 2011, p. 78).

Para la segunda, la Ordenación Manuelina, de 1521, en el Libro V, Título XII, previa la tipificación anterior de sodomía, pero innovaba en la previsión de que todos los bienes de las personas que pecasen en esta práctica serían confiscado por la Corona Portuguesa, por más que existiesen ascendentes o descendentes, quedando los últimos como condenados moralmente en sociedad por las prácticas de sus familiares. Además de prever las incentivas de que las personas delatasen a todos que supiesen realizar tales prácticas, con la previsión de premios para los informantes del Reino, que podrían recibir dinero o, incluso, hasta un tercio de la propiedad del acusado que informara previamente. Las personas que tomasen conocimiento y no delatasen a la Corona, tendrían como pena la perdida de todos sus bienes y la expulsión de los Reinos de Portugal (DO BOMFIM, 2011, p. 78).

La tercera referencia está prevista en la Ordenación Filipina de 1603, con perspectivas sobre la condena de la homosexualidad en su Libro Quinto, Título XIII, con la previsión de que todos los que practicasen el pecado de la sodomía, como condena impuesta la muerte en la hoguera. La distinción frente a las otras Ordenaciones previas era que los descendentes no se quedarían más como infames y sufrirían prejuicios o discriminación en los casos de recibir las sucesiones, y pudiendo heredar de sus ancestros muertos. En este ordenamiento también había la previsión del pecado de molicie, que consistía la práctica de masturbación entre personas del mismo sexo, con castigos graves (DO BOMFIM, 2011, p. 79-80).

Para ese momento histórico, se hace importante comentar que a partir del siglo XVI, el Santo Oficio ha realizado diversas visitas al Nuevo Mundo, más específicamente a Brasil, recibiendo innumerables denuncias sobre personas homosexuales. Muchas de las mismas han sido detenidas, juzgadas, perseguidas. Es importante recordar que esas personas pertenecían a todas las clases sociales, desde indígenas cristianizados, africanos esclavos y libertos, marineros, 
soldados, sacerdotes, funcionarios, etc... (VERBICARO SOARES, 2015, p. 87-8).

Para ejemplificar citaremos el caso del $1^{\circ}$ Capitán General de Brasil - Diogo de Botelho, el tesorero Mor da Sé de Bahia, Padre José Pinto de Freitas, que han sido acusados en la época de tener fama pública entre la población que hacían tocamientos, abrazaban y besaban a otros hombres, tanto a jóvenes como a adultos. Mott nos aduce que, ser homosexual, afeminado en el "nuevo continente" representaba un problema, mucho más que en el "viejo continente", una vez que era considerado como: un acto de traición a la hegemonía del sexo fuerte y a una amenaza a la manutención de la élite que dominaba (MOTT, 1997, p. 06).

Del mismo modo, las otras conductas que incentivaban las denuncias hacia a los homosexuales para recibir en cambio propiedades de los denunciados o valores en pecunia de la Corona. Todo por dar a conocer los hechos pecaminosos existentes en sociedad seguirían como en la Ordenación Manuelina (VERBICARO SOARES, 2015, p. 88).

Otros relatos de destaque a persecución y condena de la homosexualidad en la Colonia Portuguesa se dieron en el siglo XVII con la ejecución (MOTT, 1997, p. 06-7). Cuando en 1613, en la Provincia de São Luís do Maranhão, del indio Tibira de la Tribu Tupinambá, que ha sido amordazado en la boca de un canon, y que a posteriori ha tenido su cuerpo destrozado por los impactos de la explosión, bajo la justificativa de que con su muerte, la tierra sería purificada de sus maldades. Los indígenas hombres que eran homosexuales eran llamados de "tibira" y las mujeres lesbianas de "çacoaimbeguira" (BERNARDO, 2015, p. 42-5). Otro relato histórico ha sido en 1678, en la Capitanía de Sergipe, un joven esclavo negro ha recibido azotes hasta su muerte por practicar la sodomía (MOTT, 1997, p. 06-7). Del mismo modo en que distintos relatos en que lesbianas también han sido sometidas a castigos físicos y situaciones vejatorias en público por tener la orientación del deseo homosexual. La práctica de la sodomía era considerada tan grave que por ejemplo, en las Constituciones del Arzobispado de Bahia, de 1704, la conducta comentada era considerada como la más torpe, sucia y pecado más deshonesto. Que por su causa, Dios había enviado a la Tierra inundaciones, hambruna, secas y pestes (MOTT, 1997, p. 06-7).

Andrade do Bonfim (2011) nos aclara que con la independencia de la Colonia Portuguesa, Brasil, en la fecha de 7 de septiembre de 1822, convocó una Asamblea Constituyente y Legislativa del Imperio de Brasil, y con la Ley de 20 de Octubre del año siguiente, aprobada por Don. Pedro I, hacia vigorar las Ordenaciones, Regimientos, Leyes, Decretos, etc.., promulgadas en el Reino Portugués, hasta 25 de abril de 1821, mientras no se organizaba la constitución de un nuevo Código (DO BOMFIM, 2011, p. 80).

Con el adviento de la Constitución de 1824, se estableció según el artículo 179, XVIII, que serían organizados lo antes posible un Código Criminal y Civil. Siendo que en 1830, se sacará el Código Criminal del Imperio, con el Código Civil con un retraso de casi cien años más tarde que el Código Criminal. Lo que damos un especial destaque con la materialización del Código Criminal, donde la previsión de condena a la homosexualidad es suprimida del modelo originario portugués y dejó de vigorar en Brasil (DO BOMFIM, 2011, p. 80).

\section{Consideraciones finales}

Es importante destacar que hemos optado por la visibilidad histórica sobre el tema de la homosexualidad a lo largo de la propia evolución humana, llevada a cabo por factores 
culturales, políticos, sociales, religiosos que han influido en una interpretación negativa sobre esa orientación sexual desde la Edad Media, como directamente relacionada a la imagen de algo anormal, antinatural, pecaminoso, diabólico, enfermo, promiscuo e otros cualitativos. Que al final, condenaron la orientación sexual homosexual como perteneciente a una supuesta segunda categoría de la diversidad sexual.

Nuestra preocupación en retratar el tema de la homosexualidad y trabajarlo, junto con la historia, nos ha parecido relevante para construir las bases de nuestra investigación y en los argumentos presentados en el estudio.

Los hechos y las experiencias históricas nos han aportado indudablemente el pilar comprehensivo de una realidad que tiene en su pasado, muchas de las respuestas para entender el presente sobre la temática de las personas homosexuales. Así, el estudio desde la formación de un ideario sobre la homosexualidad en sí, como la idealización de prejuicios, conductas discriminadoras o procesos de exclusión social de los homosexuales han sido fundamentales para identificar los desafíos originarios desde la Edad Media, pero que siguen presentes en las Eras Moderna e Contemporánea de la humanidad.

Es imperioso reconocer que los errores del pasado siguen presentes en prácticas diarias de violencia y discriminación a la homosexualidad por el mundo. Por esta razón, es indispensable conocer los obstáculos que dificultan la vida de las personas homosexuales para buscar alternativas para verdaderos cambios de paradigmas y, también, para alcanzar la tan comentada igualdad entre todos, sin discriminaciones motivadas por orientación sexual.

\section{Referencias}

IZQUIERDO, Alejandro. Evolución del Derecho de Igualdad de Lesbianas y Gais. Trabajo de Grado. Universidad de Salamanca: Programa de Doctorado Pasado y presente de los derechos humanos, Salamanca, España, 2006.

AYENSA, José Ignacio. Estudiando La Homosexualidad. Teoría e investigación. $1^{\text {a }}$ Edición, Ediciones Pirámide. Madrid, España: Ediciones Pirámide, 2008.

BERNARDO, André. Amor de índio. In: Revista Aventuras na História: a revolução cantada. Edição 146, Setembro. São Paulo, Brasil, 2015.

DO BOMFIM, Silvano. Homossexualidade, Direito e Religiáo: pena de morte à uniáo estável. A criminalizaçáo da homofobia e seus reflexos na liberdade religiosa. In: Revista Brasileira de Direito Constitucional - RBDC n. 18 - jul./dez. Brasil, 2011.

MALUCELLI, Laura; FO, Jacopo; TOMÁT, Sérgio. O Livro Negro do Cristianismo. Dois mil anos de crimes em nome de Deus. Disponible en: <http://jandirainbow.files.wordpress. com/2010/05/o_livro_negro_do_cristianismo_-_jacopo_sergio_laura_malucelli_.pdf $>$. Acceso en: 14 mar. 2021.

MOTT, Luiz Roberto. Homofobia. Aviolção dos Direitos Humanos de Gays, Lésbicas \& Travestis no Brasil. Grupo Gay Da Bahia / International Gay and Lesbian Human Rights Commission. Salvador. Bahia, Brasil, 1997.

ROBERT, Jean-Noel. Eros Romano. Sexo y moral en la Roma antigua. 1a Edición. La 
mirada de la historia. Editorial Complutense. Madrid, España, 1999.

VERBICARO SOARES, Douglas. La libertad sexual en la sociedad: especial referencia a la homosexualidad en las Fuerzas Armadas Brasileñas. Salamanca, España. Tesis Doctoral. Universidad de Salamanca - USAL: Programa de Doctorado Pasado y Presente de los Derechos Humanos. 791 p. 2015. 